\title{
DESCONTINUIDADE E SIMULTANEIDADE: OS FRAGMENTOS RECOLHIDOS PELA MONTAGEM CINEMATOGRÁFICA EM THE BUENOS AIRES AFFAIR, DE MANUEL PUIG
}

Bárbara Cristina Marques. Doutoranda em Estudos Literários pela Universidade Estadual de Londrina. Mestre em Estudos Literários (UEL). Professora de Literatura do Curso de Letras da Universidade Norte do Paraná, em Londrina.

\section{RESUMO}

Se o fenômeno das adaptações literárias para o cinema tornou-se uma prática comum, surge com vigor considerável a escrita de textos literários contaminada pela linguagem fílmica. Como tentativa de avaliar essa literatura contemporânea, devoradora de outros modos de percepção e apreensão de uma realidade que se dá através do 'ver', propomos neste artigo uma análise do romance The Buenos Aires Affair, do escritor argentino Manuel Puig, a partir do uso da técnica da montagem como princípio não apenas organizador da narrativa, mas, sobretudo, como um tipo de procedimento que confere a produção de sentido da obra.

PALAVRAS-CHAVE: The Buenos Aires Affair; Montagem; Linguagem Fílmica

\section{ABSTRACT}

If the phenomenon of literary adaptations in cinema has become an ordinary practice, the writing of literary texts contaminated by filmic language rises with meaningful strength. As an attempt to evaluate this contemporary literature, devourer of other ways of reality perception and apprehension which comes through the 'seeing', in this article we propose an analysis of the novel The Buenos Aires Affair, from argentinean writer Manuel Puig, viewing the montage technique not only as a narrative organizing principle, but mostly as a kind of procedure that gives meaning to the work.

KEYWORDS: The Buenos Aires Affair; Montage; Filmic Language

montagem:

ver apenas aquilo que

pode ser visto

(não dito

não escrito)

a explosão atômica no

alto da colina daqueles

que só vivem uma vez

alcançará

o céu e os bosques daqueles

que seguem a regra do jogo

antes que ecloda a guerra

mundial.

(as fotos como radiografia

da doença)

Jean-Luc Godard 


\section{Introdução}

A aproximação da literatura com os meios de comunicação de massa, em especial com os audiovisuais - cinema e televisão, tem provocado ao longo do século XX, e ainda provoca, avaliações que giram em torno de uma preocupação levantada por Walter Benjamin (In LIMA, 1982) nas primeiras décadas do século $\mathrm{XX}$, isto é, a relação entre arte e técnica. A partir dos novos meios de comunicação, a literatura mostrou-se aberta a outros procedimentos criativos. $\mathrm{O}$ campo de investigações para estas duas matrizes estético-culturais é, sem dúvida, bastante amplo e propenso às mais variadas avaliações, tanto no que diz respeito às teorias quanto aos estudos comparados entre literatura e cinema.

Em geral, os estudos que refletem sobre esta prática intersemiótica e xibe m frequentemente uma preocupação quanto às adaptações cinematográficas ou a transposição da literatura para a linguagem audiovisual. Os textos que se ocupam dessa tarefa apresentam-se muito pontuais ao explorar as tensões mais comuns entre a narrativa literária e a narrativa cinematográfica, tais como o critério de fidelidade, os prejuízos e ganhos acerca da representação/interpretação, as intenções do realizador, a re-criação fílmica (que pode suscitar uma espécie de autonomia cultural do filme em relação à obra literária), a questão mercadológica, o dialogismo cultural, entre outros.

Ainda que a relação entre estas duas linguagens estéticas se equacione num contexto de mão-dupla, os olhares mais cuidadosos acerca da contaminação da literatura contemporânea por códigos estéticos caros ao cinema é, pode-se dizer, um fato relativamente novo. Isso se justifica, sem dúvida, pela propagação da cultura de massa e suas novas formas de expressão e apreciação dos objetos culturais.

Grande parte de escritores contemporâneos têm sido atraídos pelas inúmeras potencialidades apresentadas pelo cinema como uma espécie de solução técnica para construir uma ficção mais "ligada à vida presente [...] mais em consonância com o tempo e os ritmos da vida moderna" (PIRES, 1992, p. 99). Não raro, muitos desses escritores transitam entre o roteiro e a literatura. Esse dialogar com o cinema por meio de uma narrativa que mimetiza a forma e a linguagem de um roteiro cinematográfico, propiciando ao leitor a 'sensação' de 'ver' as imagens e os movimentos narrados, apresenta-se como um cruzamento de fronteiras dos quais fazem parte os textos de brasileiros como Rubem Fonseca, João Gilberto Noll, Fernando Bonassi, Valêncio Xavier, Marçal Aquino, Caio Fernando Abreu, Edgard Telles Ribeiro, Ivân Angelo, Sérgio Sant'Anna, Silviano Santiago e Bernardo Carvalho. Outros escritores latino-americanos como Manuel Puig, Mario Vargas Llosa, Guillermo Arriaga e Pedro Juan Gutiérrez, por exemplo, ao imprimirem em suas obras essa absorção de um status de câmera, provocam textualmente um ritmo, um teor e um timing, por vezes, mais cinematográfico e menos literário. 
Se pensarmos em romances que se situam no limiar entre literatura e cinema, vale lembrar da entrevista de Guillermo Arriaga concedida à Revista Cult, em junho de 2007: "Considero o que faço em romance e em cinema a mesma coisa: literatura [...] Sou um escritor que escolhe modos diferentes de contar uma história, que pode ser um romance ou um filme" (ARRIAGA, 2007, p. 9). A observação do autor de Um doce aroma de morte, romance publicado no Brasil em 2007, dos roteiros de Amores Sujos (2000), 21 gramas (2003) e Babel (2006) faz com que nos questionemos a respeito do vigor com que a ficção contemporânea tem sido tributária de uma arte híbrida que "consiste também num gesto de dessacralização da instituição literária como campo autônomo [...], construindo-se na fronteira" (FIGUEIREDO, 2007, p. 11).

O processo de justaposição de imagens, a inferência dos códigos visuais espetacularizando a dinâmica da ação dramática, a narrativa construída em planos, enquadramentos, apontando diferentes angulações, mudanças constantes de focalização e a utilização de técnicas de montagem e decupagem, enfim, a "experiência perceptiva visual, a qual não mais repousa na perspectiva única do indivíduo que vê" (PELLEGRINI, 2003, p. 19), fazem com que a ficção contemporânea seja delineada por meio de flashes que capturam a imagem numa espécie de jogo ótico, resultado do intercâmbio entre a película e a literatura.

A construção de uma literatura permeada por técnicas cinematográficas tomou corpo com muito mais vigor a partir da década de 80 quando os procedimentos de escritura se tornaram cada vez mais híbridos (BARBIERI, 2003). Cresce a importância das referências aos mitos da cultura de massa, acentua-se a propagação das imagens, aumenta o ritmo narrativo, multiplicamse as linguagens. E, se os artifícios do cinema na ficção contemporânea revelam uma literatura aberta aos audiovisuais, também podemos falar de uma mudança quanto à percepção do 'leitor-espectador'. As consequências desses empréstimos, que possibilitam a "cinematografização" (CESAR, 1993, p. 68) da linguagem literária até o seu limite, promovem um tipo de obra que adota uma perspectiva simulada da realidade construindo o discurso através da fragmentação e dos recursos da montagem. Como pontua Sganzerla (2001, p. 35), "verifica-se, tanto no cinema quanto no romance contemporâneo, uma acentuada preocupação pela visão, pelo olhar, como forma de captação da realidade."

Da mesma forma que a literatura sempre compareceu no cinema desde seu aparecimento, a arte cinematográfica tem frequentado cada vez mais as páginas de textos literários que surgem "indefiníveis",

romances que mais parecem reportagens; contos que não se distinguem de poemas ou crônicas, semeados de sinais e fotomontagens; autobiografias com tonalidade e técnica do romance; narrativas que são cenas de teatro; textos feitos com a 
justaposição de recortes, documentos, lembranças, reflexões de toda a sorte. (CÂNDIDO, 2003, p. 190).

A pluralidade, que parece ser a palavra de ordem da contemporaneidade, torna-se condição primeira de textos que justapõem, numa espécie de colagem e bricolagem, discursos e materiais provenientes de diversos âmbitos culturais. Certamente influenciados pelo cinema, arte que proporcionou a imagemmovimento, esses textos "indefiníveis" impuseram ao leitor uma nova forma de leitura que, agora, implica o apuro do olhar.

Seja no argumento ou na forma, o cinema cristalizou-se no objeto literário, assinalando uma escritura cujo movimento ou fluxo se assemelha ao movimento de uma câmera, onde é preciso estar atento à junção dos fragmentos.

A experimentação de uma linguagem literária mais propensa às inovações trazidas pelo cinema resultou em obras cuja narrativa se tornou mais ágil, privilegiando os cortes abruptos de frases que sugerema economia dos roteiros, a fragmentação, a potencialização de recortes de cenas e personagens particularizados pelo procedimento dos close-ups, novas apresentações do espaço-temporal, os deslocamentos de focalização, enfim, histórias sendo montadas e desmontadas ou mostradas de vários ângulos, sob várias perspectivas.

\section{The Buenos Aires Affair: a construção da narrativa pela montagem}

A atração pelo cinema se fez presente desde muito cedo na vida do escritor argentino Manuel Puig (1932-1990). Nascido na pequena General Villegas, Puig cristalizou o universo cinematográfico em toda sua obra, vinda a público com a publicação do romance La Traicíon de Rita Hayworth, em 1968, e, posteriormente, com Boquitas Pintadas (1969), The Buenos Aires Affair (1973), El beso de la mujer araña (1976), Pubis Angelical (1979), Maldición eterna a quien lea estas páginas (1981), Sangre de amor correspondido (1982), Cae la noche tropical (1988). ${ }^{[1]}$

A relação com os artefatos do cinema constitui uma realidade tão patente na criação literária de Puig que as vozes narrativas e discursivas nos romances confundem-se com a do próprio escritor.

A singularidade da obra de Puig reside numa pluralidade de vozes e elementos que fazem ecoar uma tensão entre o erudito e o massivo, entre o canônico e o periférico, tendo no cinema tipo $B$, no melodrama à moda folhetinesca, na radionovela, nas histórias policiais, nos boleros e tangos e na pornografia barata uma espécie de modelo de um imaginário coletivo.

Puig trabalhou em toda a sua produção com a apropriação destes elementos massivos, empreendendo uma renovação ao gênero ficcional contemporâneo por meio da multiplicação do espaço discursivo; promoveu um 
outro tipo de canal polissêmico, cujas vozes viriam do seio da classe média. Isto aponta para o esvaziamento da existência sociocultural de personagens, cuja consciência alienante é reificada pelos meios de comunicação de massa. Assim, ajusta às formas literárias conhecidas um universo concebido e digerido pela massa - a novela policial, a telenovela, os roteiros de película cinematográfica, em particular os advindos da fábrica hollywoodiana, as letras desprestigiadas de canções populares, como o tango e o bolero, e até o folhetim, homologado historicamente dentro da tradição literária.

Interessante observar que Puig faz uso dessa imbricação de maneira a promover um sentido novo à literatura, desmistificando a complexidade do cânone. Na verdade, Puig estabelece uma nova ordem ficcional ao sucumbir a narrativa a esse vasto repertório contemporâneo, enfatizando uma mecânica que atenderia as exigências de um público consumidor. À narrativa de Puig interessa, portanto, o problema do ambiente opressor que causa os mass media no sujeito, inconscientemente aprisionado. A heterogeneidade dos elementos e a mistura justaposta dos gêneros narrativos fazem emergir dos romances uma prosa kitsch, automatizada pelo gosto cafona da cultura de massa; um tipo de processamento de degradação da obra de arte por conta do uso de clichês, mas que, em Puig, ganha novo sentido.

Desde a publicação de L a traicíon de Rita Hayworth, os elementos intrínsecos à estética cinematográfica foram explorados não apenas como uma espécie de imaginário coletivo, mas, sobretudo, como forma de engendrar um novo procedimento de escritura. A produção de sentido nos romances ocorre, então, de maneira análoga à montagem cinematográfica.

Ainda que o princípio da montagem não se aplique apenas ao cinema, a partir das teorias de Eisenstein, mesmo com algumas discordâncias no campo analítico-teórico, a montagem tem sido tratada como uma técnica própria da estética cinematográfica. Segundo Christian Metz (1977, p. 47), a montagem, nas décadas de 20 e 30, tornou-se um tipo de recurso clicherizado, como se houvesse uma espécie de "fanatismo da montagem". Isso se explica pelo modo com a montagem empreendeu uma concepção de arte em geral no século XX. Esse processo de ajustar, organizar, unir os fragmentos, possibilitado pela técnica da montagem, animou boa parte de artistas nas mais diferentes expressões estéticas pela forma como, a partir do advento cinematográfico, pôde-se empreender uma nova maneira de criar objetos, fosse na pintura, fosse na poesia, fosse na narrativa literária.

Conhecido como um dos nomes mais representativos da cinematografia mundial, o cineasta Serguei Eisenstein (1898-1948) publica, em 1923, o seu artigo - espécie de manifesto - "Montagem de atrações" que revoluciona o pensamento artístico ao propor a montagem como um recurso fundamental na produção de sentido de uma obra. A montagem entendida por Eisenstein seria uma espécie de força geradora de sentido para a narrativa fílmica e não 
propriamente sua linearidade. O espectador, nesse caso, participaria dessa construção como sujeito ativo. Um dos aspectos mais revolucionários com relação à teoria do cineasta consistia na quebra programática da linearidade narrativa, possibilitando, então, o processo de descontinuidade. Isso porque o cinema na sua forma clássica pretendia um tipo de verossimilhança dos acontecimentos narrados. Para Eisenstein (1969, p. 72), "a junção de duas pontas quaisquer de filme resulta infalivelmente numa representação nova, significando essa justaposição uma qualidade nova".

As palavras em liberdade, a desarticulação da sintaxe e as imagens choque, patrimônio comum das vanguardas das primeiras décadas do século particularmente utilizado pela geração que se convencionou chamar impropriamente a do "cubismo literário" (1917-1920), acham-se interligados no procedimento característico mais geral da arte moderna: a técnica de justaposição ou montagem, em que se relacionam elementos heterogêneos, sem ligações diretas entre si. (NUNES In ÁVILA, 1975, p. 45).

O procedimento da montagem comparece em The Buenos Aires Affair, terceiro romance de Puig e objeto de análise deste artigo, como técnica fundamental que organiza os fragmentos e episódios da narrativa, mas principalmente como o recurso que estabelece a produção de sentido do texto. Poderíamos dizer que tal manipulação da linguagem neste romance, através da incorporação de um dispositivo fílmico como o da montagem, proporciona o ajuste de eventos aparentemente desconexos.

No romance subjaz uma trama aparentemente sem nenhuma causalidade de fatos. A história de Gladys Hebe D'Onofrio, uma artista plástica frustrada que, após um longo tempo em Nova Iorque, retorna a Buenos Aires em razão de uma crise nervosa, e Leo Druscovich - crítico de arte que desde a infância apresenta os sintomas do sadismo - é dada a partir de um enredo que mistura uma variedade de técnicas narrativas.

A história é situada em locais diversos, colocando os personagens ora na metrópole, ora na província. A Buenos Aires cabe a representação de uma classe média tipicamente portenha, na qual se inserem os conflitos socioculturais da pequena burguesia - a decadência econômica da família de Gladys d'Onofrio com a morte do pai e a desestruturação da família de Leo Druscovich também pela perda dos pais. Nova Iorque, por sua vez, ressalta o ambiente mais promissor da metrópole com suas tecnologias, museus e ofertas de emprego rápido. Playa Blanca se dá como o refúgio para os problemas psicológicos de Gladys. Estes intercâmbios apontam, sem dúvida, para o redimensionamento espacial de um sistema que se torna global.

The Buenos Aires Affair é, antes de mais nada, uma novela à moda policial que, revestida pelos elementos simbólicos dos mass media, focaliza em primeiro plano uma espécie de exibicionismo machista travestido pelas práticas sexuais - 
tão censuradas no período da ditadura militar. O romance sugere uma discussão implícita à hierarquização que a sociedade impõe aos gêneros sexuais. Interessante notar que Puig trabalha nesse romance a fim de que o leitor destine sua atenção a um crime que, afinal, jamais acontecerá, suprimindo, assim, as imagens degradadas da sexualidade das personagens. $\mathrm{O}$ assassinato que de fato ocorre, quando Leo, na tentativa de saciar um de seus desejos sexuais, comete um crime seguido de estupro, produz mais impacto na psique conturbada de Leo do que na narrativa.

A sexualidade de Leo, por exemplo, não só revela o gosto pela violência, buscando sempre uma relação sádica, mas uma perturbação psicológica. O mesmo se dá com Gladys que, com sua busca sentimental bem ao estilo melodramático, troca diversas vezes de parceiro, explorando sempre o sexo tanto como realização de um instinto, bem como tentativa de superar traumas.

Os diferentes episódios, montados como uma sequência de imagens, são todos abertos com cenas de filmes hollywoodianos clássicos das décadas de 30 e 40 que, de alguma forma, mantêm uma relação de causalidade com os acontecimentos destes espisódios. Cada episódio tem na trama enfoques distintos, permitindo ao leitor conhecê-la a partir de focos também distintos. Isso se explica pelo fato de o narrador (3a pessoa) se ausentar em diversos capítulos, deixando os próprios documentos falarem por si mesmos. Assim, podemos pensar naquela mesma ausência de narração do cinema como um procedimento que confere veracidade e objetividade à narrativa. A verdade de um filme ocorrerá, então, justamente por não haver uma voz que diga ao espectador se tratar de uma obra de ficção. É como se essa "cinematografização do texto literário" em The Buenos Aires Affair, em parte propiciada pela ausência da figura do narrador em alguns momentos, exigisse do leitor um comportamento de espectador. Essa sensação de 'ver', como se estivéssemos diante da exibição de um filme, ocorre justamente pela composição fragmentária de cada capítulo, mesmo quando há a presença do narrador.

(Capítulo V)

Buenos Aires, 8 de maio de 1969

Um escritório do Departamento de Polícia. À direita, junto de uma janela sem cortinas, uma mesa mesa moderna com telefones, máquinas de escrever e gravador; à esquerda uma mesa mais simples, com um só telefone. Não se sabe se é de noite ou de dia, devido às venezianas fechadas; em cima das mesas estão duas lâmpadas acesas. Um homem de meia idade, vestido com esmero, sentado à secretária de mais categoria, trata de concentrar-se na leitura de um artigo intitulado "ATAQUE ISRAELENSE A PORT SAID" da primeira página do jornal do dia.

Assistente: (homem já mais velho, de cabelo grisalho, e figura rechonchuda, protegido da forte luz da lâmpada por uma viseira, atende o telefone) Sim, sim senhorita (a seu superior). Para o 
senhor, chefe. Uma mulher.

Oficial: (levanta o fone) Fale.

Voz no telefone:

Oficial: Sim, estou ouvindo (seu olhar recai sobre um título do jornal - "ÚLTIMAS BAIXAS DOS ESTADOS UNIDOS" - e percorre parte do texto que se segue sem se concentrar, dando atenção apenas à sua interlocutora).

Voz:

Oficial: para consultas aqui está meu assistente, tornou a passarlhe o fone.

Voz:

Oficial: Perigo de que espécie? Antes de mais nada dê-me seu nome.

Voz:

Oficial: Prometemos reserva absoluta (PUIG, 1975, p. 63 - grifo do autor).

No episódio acima (Capítulo V), aberto com uma cena de Jantar às oito (Dinner at Eight - 1933), há a descrição de uma denúncia de um suposto crime que deve ser decodificado pelo leitor a partir da fala do Oficial e do Assistente, uma vez que não há a descrição do relato do delator, identifcado apenas como "Voz". O primeiro ponto que devemos considerar neste trecho, e que se repetirá em vários momentos do romance, é a forma como Puig roteiriza a escritura literária. São descritos, assim, não apenas a cena, o acontecimento em si, mas o enquadramento, a posição de cada personagem, o ambiente, os movimentos dos personagens. Vale lembrar que o roteiro cinematográfico é "uma tentativa sistemática e ordenada para prever o futuro filme" (BARBARO, 1965, p. 118). Ainda que elaborado verbalmente, o roteiro destina-se a uma linguagem visual, daí a existência dos registros da ação dramática em si, da psicologia dos personagens, dos gestos, da luz, e tantos outros elementos que irão permitir a visualização da história.

No romance The Buenos Aires Affair, a recorrência aos intertextos fílmicos, cujo esboço de relatos, diálogos e fatos ocorre à maneira do roteiro cinematográfico, espetaculariza a dinâmica da narrativa numa espécie de sucessão de imagens que necessita do recurso da montagem para que o sentido da obra se realize.

As unidades espaço-temporais também são alteradas em razão de 'cortes' que quebram a linearidade da evolução narrativa tornando-a absolutamente descontínua. É claro que não podemos esquecer que The Buenos Aires Affair é um romance à moda do policial e, nesse caso, a inversão da estrutura narrativa é fundamental para incitar a curiosidade do leitor e manter o caráter investigativo e adivinhatório do gênero.

No entanto, essa falta de linearidade, quando observados os fragmentos separadamente, como se se tratassem de pequenas histórias, é obliterada através da justaposição de elementos aparentemente desconexos. No romance, cada capítulo mostra-se independente ou paralelo, de modo que o texto pareça 
lacunar.

O livro inicia-se com o desaparecimento de Gladys em Playa Blanca. Em seguida, tem-se a narração de uma cena de aparente tortura sexual, já em um apartamento em Buenos Aires. Um corte é feito. A partir daí, tem início a narração dos "Acontecimentos Principais da Vida de Gladys" (Capítulo III), todo separado por pequenos subtítulos: "Mãe e filha"; "Pai e filha"; "Vocação"; "Primeiros bailes"; "Nova Iorque", etc. Em meio aos relatos biográficos de Gladys e Leopoldo Druscovich filho ("Acontecimentos Principais da Vida de Leo" Capítulo VI), mais um corte e outra cena 'estranha' para o leitor: um telefonema anônimo que intenta denunciar um crime, como vimos no trecho acima referente ao Capítulo V. Seguem-se, assim, vários outros cortes que aceleram ou antecipam a ação dramática. Como uma espécie de quebra-cabeça, o romance vai sendo montado e desmontado. Pode-se ver a história a partir de vários pontos-de-vista.

De acordo com os princípios teoréticos de Eisenstein, a montagem organiza os conflitos que, uma vez justapostos, permitem a criação de um terceiro e novo valor. Através da montagem, o escritor consegue intensificar a ruptura do tempo linear, controlar o ritmo da narrativa, trabalhar com alternâncias de discursos e objetos.

No romance, muitos capítulos são datados justamente para mostrar o paralelismo em que ocorrem as ações. Essas inscrições reafirmam o uso da técnica da montagem na narrativa. Nos dois primeiros capítulos, têm-se as marcações: "Playa Blanca, 21 de maio de 1969" / "Buenos Aires, 21 de maio de 1969". Logo no início, percebemos estar diante de dois acontecimentos que ocorrem concomitantemente. Mas só descobrimos a ligação entre eles muito tempo depois. Ao longo do romance, essas datas alternam-se para o passado ou para o futuro e só aparecem para marcar acontecimentos da trama. Nos capítulos destinados à biografia dos dois protagonistas, por exemplo, estas datas são dispensadas, entretranto, a narração se divide em temas, desconstruindo mais uma vez a idéia de continuidade ou tempo linear. É através da montagem, então, que as relações vão sendo estabelecidas.

Já falamos anteriormente de um modo particular de escrita atribuído a Puig como a mistura de diferentes registros de narração e documentos que faz da obra do escritor uma espécie de canal polissêmico. Em The Buenos Aires Affair, a mescla destes registros serve tanto para pontuar os capítulos, como para marcar o corte entre cenas e sequências que, muitas vezes, acontecem dentro dos próprios capítulos.

Buenos Aires, abril de 1969

... minhas unhas tratadas, não compridas, pintadas de rosa clâmen, limpas, sãs e fortes, têm a beira lixada mas não afiada e o lençol, cuja côr é impossível recordar na penumbra, cobre os desenhos do colchão. [...] A coxa e o joelho escorregam 
lentamente pelo lençol em direção a uma beirada da cama que limita com a parede, param um instante e voltam a seu lugar. A pele está um pouco mais fresca que os lençóis mornos, e da pele para dentro a polpa cada vez mais morna por causa do contato com os ossos quentes [...]. Fechando os olhos também é possível que se escute um ligeiro arquejar, não, naquele momento os dois corpos se encontram em repouso.

Entrevista que uma repórter da revista de modas de Nova Iorque "Harper's Bazaar" fez com Gladys, segundo imaginação dela enquanto descansava junto de Leo que dorme.

Repórter: Para ganhar totalmente sua confiança - eu sei, a senhora é tímida - vou-lhe permitir escolher o título deste artigo. Gladys: Eu não saberia o que responder.

R: O que é que acha "Gladys Hebe D'Onofrio está no céu"?

G: Acho um título realista e acertado. Mas vamos dirigir-nos a seus leitores numa linguagem chique e internacional, "The Buenos Aires Affair" será o título (PUIG, 1975, p. 95-96 - grifo do autor).

No trecho acima, Capítulo VII, temos a narração de vários discursos que se operam pelo procedimento da montagem. No primeiro deles, alternam-se os narradores. Na verdade, parece haver uma mistura entre uma narração de Gladys, nesse caso uma narração em $1^{\text {a }}$ pessoa, e apenas divagações da protagonista. O foco muda de repente e temos novamente o narrador em $3^{a}$ pessoa. Em seguida, novamente como em um roteiro, temos a indicação de uma entrevista imaginada pela personagem. A partir daí segue a entrevista na qual são apresentadas ao leitor as facetas da personalidade de Gladys. Essa multiplicação do espaço discursivo com constantes mudanças de focalização dinamiza a evolução da narrativa. Em muitos momentos do livro, como este citado acima, a narrativa evolui através de flashes e fragmentos organizados de modo irregular. O procedimento técnico da montagem, então, não aparece apenas para ajustar. Serve antes como um recurso que empreende uma nova percepção do espaço narrativo.

\section{Considerações finais}

Todos essas observações apontam para, a partir da relação que a literatura estabeleceu com o cinema, uma nova concepção de arte na contemporaneidade. O modo como muitos textos valeram-se dos artefatos cinematográficos tem mostrado "o emprego cada vez maior de novas formas de visualidade, advindas, sobretudo, do papel preponderante que a imagem assume em nossa cultura" (VIEIRA, 2007, p. 19). Sem dúvida, na ficção contemporânea a imagem é onipresente, e, nesse sentido, a leitura da realidade 
que passou a fazer o autor contemporâneo tornou-se mediada pelos signos dos mass media, conduzindo, como ressalta Kellner (2001), a um novo tipo de autonomia cultural.

\section{Referências:}

ARRIAGA, Guillermo. Guillermo Arriaga, para ler e para ver. Revista Cult, São Paulo, ano 10, n. 114, p. 8-11, jun. 1997.

BARBARO, Umberto. Elementos de Estética Cinematográfica. Trad. Fátima de Sousa. Rio de Janeiro: Civilização Brasileira, 1965.

BARBIERI, Therezinha. Ficção impura: prosa brasileira dos anos 70, 80 e 90 . Rio de Janeiro: Ed. UERJ, 2003.

BENJAMIN, Walter. A obra de arte na era de sua reprodutibilidade técnica. In: LIMA, Luis Costa (Org.). Teoria da cultura de massa. Rio de Janeiro: Paz e Terra, 1982.

CÂNDIDO, Antônio. A nova narrativa. In: A educação pela noite e outros ensaios. São Paulo: Ática, 2003.

CESAR, Ana Cristina. Um livro cinematográfico e um filme literário. In:

Escritos no Rio. Rio de Janeiro: Ed. UFRJ; Sâo Paulo: Brasiliense, 1993.

EISENSTEIN. Serguei. Reflexões de um cineasta. Trad. Gustavo A. Dória. Rio de Janeiro: Zahar, 1969.

FIGUEIREDO, Vera Lúcia Follain de. Roteiro, literatura e mercado editorial: o escritor multimídia. Revista Ciberlegenda, ano 9, n. 17, maio 2007, p. 1-15.

KELLNER, Douglas. A cultura da mídia - estudos culturais: identidade e política entre o moderno e o pós-moderno. Trad. Ivone C. Benedetti. Bauru: EDUSC, 2001.

METZ, Christian. A significação no cinema. São Paulo: Perspectiva, 1977.

NUNES, Benedito. Estética e correntes do Modernismo. In: ÁVILA, Afonso (Org.) O Modernismo. São Paulo: Perspectiva, 1975.

PELLEGRINI, Tânia et al. Literatura, cinema e televisão. São Paulo: Senac; São Paulo: Itaú Cultural, 2003.

PUIG, Manuel. The Buenos Aires affair. Trad. de Glória Rodríguez. Rio de janeiro: Civilização Brasileira, 1975.

SGANZERLA, Rogério. Por um cinema sem limite. Rio de Janeiro: Azougue, 2001.

VIEIRA, André Soares. Escrituras do visual: o cinema no romance. Santa Maria: Ed. UFSM, 2007. 
